\title{
Common Misconceptions About Autism Spectrum Disorder Management - Review Article
}

\author{
Naseem Alhujaili
}

Division of Psychiatry, Department of Internal Medicine, Rabigh Faculty of Medicine, King Abdulaziz University, Jeddah, Saudi Arabia

\author{
DOI: $10.36348 /$ sjmps.2019.v05i11.007 \\ | Received: 07.11.2019 | Accepted: 14.11.2019| Published: 16.11 .2019 \\ *Corresponding author: Naseem Alhujaili
}

\section{Abstract}

Autism Spectrum Disorder (ASD) is a neurodevelopmental disorder characterized by a deficit in social communication, as well as restricted interests and repetitive behaviours. Various misconceptions about ASD management are rising, leading to parent's confusion and suffering and possible serious harm to ASD patients. This review aims to shed light on common misconceptions about ASD management, including the relationship between ASD and vaccines, the use of chelation therapy, hyperbaric oxygen therapy and gluten-free diet. In conclusion, there is no evidence of a link between vaccinations and the development of ASD, as well as no evidence to support using chelation therapy, hyperbaric oxygen therapy and a gluten-free diet, but rather there is evidence of harm. Educating parents to weigh the benefits and risks is a vital role for any health care provider.

Keywords: Autism, vaccines, chelation, hyperbaric oxygen, gluten-free, misconceptions.

Copyright @ 2019: This is an open-access article distributed under the terms of the Creative Commons Attribution license which permits unrestricted use, distribution, and reproduction in any medium for non-commercial use (NonCommercial, or CC-BY-NC) provided the original author and source are credited.

\section{INTRODUCTION}

Autism Spectrum Disorder (ASD) is a neurodevelopmental disorder characterized by a persistent deficit in social communication and interaction, as well as restricted interests and repetitive behaviours. Researchers suggest that there are nonspecific environmental risk factors. In addition to polygenic causes, and heritability estimates ranged from $37 \%$ to higher than $90 \%$ [1].

There is no cure for autism, and no medication to treat it. The most available evidence is toward early intensive behavioural intervention. Also, medication can be combined to treat comorbid symptoms [2]. Given that no single cause and still no cure for ASD, this leads to the developing of many misconceptions to fill the gap.

This review aims to summarize the common misconceptions about ASD management and the evidence against those misconceptions. It includes the relationship between ASD with vaccines, chelation therapy, hyperbaric oxygen therapy and a gluten-free diet.

\section{ASD and Vaccines \\ Over several years, a concern has been raised regarding the potential links of vaccinations with the}

development of ASD. The most common vaccination that has received the critique is the measles, mumps, rubella (MMR) vaccine.

CDC reported 17 measles outbreaks in the U.S. in 2011 when parents and health care providers decided to opt-out of the MMR vaccination schedule because of concerns regarding the development of ASD [3].

A 1998 study that links autism with vaccines has been retracted and epidemiologic studies that support a link demonstrated significant methodological limitations that invalidate their conclusions [4].

A meta-analysis of five case-control and five cohort studies reported no increased risk of developing ASD following MMR exposure [5].

A Canadian study compared the incidence of ASD before and after discontinuation of the use of thimerosal, an organic mercury-containing compound in vaccines. They found the prevalence of ASD increased by $10 \%$ annually over the ten years of the study despite the decrease in the administration of the MMR vaccine. They contributed the rise in ASD diagnosis to increased awareness and broadening of diagnostic criteria [6]. 
Educating the parents to weigh the benefit and risk by explaining that there is no evidence to suggest the link between ASD and vaccination compared to increasing the risk of catching potentially lifethreatening infectious diseases is a vital role for health care providers [5].

\section{ASD and Chelation Therapy}

The hypothesis behind using chelation therapy is back to the 1998 study, which links autism with MMR vaccine exposure. Although the study had been restricted and no further evidence to support this hypothesis, chelation therapy is still used to withdraw specific metals from the person's body [7].

Chelation therapy can lead to serious side effects, including fever, vomiting, diarrhea, cardiac arrhythmias and hypocalcemia. From 2003 to 2005, 3 deaths had been reported as a result of hypocalcemia after intravenous chelation therapy [8,9].

A systematic review for five studies does not support the use of chelation as a treatment for ASD, given the small number of studies and their methodological weaknesses, in addition to mixed and negative results about the evidence for its efficacy in the ASD population [10].

\section{Hyperbaric Oxygen Therapy (HBOT)}

HBOT is a treatment in which the patient breathes a higher concentration of oxygen delivered in a chamber or tube. It has been thought that autistic patients will benefit from increasing cerebral perfusion during the treatment $[11,12]$.

A review of eight studies, including three randomized controlled trials, does not support HBOT as an effective treatment for ASD [13-15].

In 2017, the Food and Drug Administration published a warning for parents regarding false or misleading claims about HBOT for treating ASD [16].

\section{Gluten-Free, Casein-Free Diets for all ASD cases}

Many parents prefer to use alternative treatments as they generally perceived as risk-free. The most common alternative treatment is a gluten-free, casein-free diet.

Important points to take into consideration are ASD children can be a picky eater and restricting their diet can lead to more serious nutritional deficiencies. Besides, having a special diet is an isolating factor that interferes with the aim to improve the social integration of ASD children [17].

A systematic review concluded that even the few studies that reported positive evidence they were based on small sample sizes, which is reducing their validity. The rest of the studies reported negative results about this type of dietary intervention.

Given that the evidence is currently limited and weak, it's recommended that it should be only used if there is evidence for an intolerance or allergy to foods containing the allergens excluded in gluten-free, caseinfree diets [18].

\section{CONCLUSION}

Knowing the evidence against common misconceptions related to ASD management is essential for health care providers to educate parents, teachers and the public. There is no evidence of a link between vaccinations and the development of ASD, as well as no evidence to support using chelation therapy, hyperbaric oxygen therapy and a gluten-free diet, but rather there is evidence of harm.

\section{REFERENCES}

1. American Psychiatric Association. (2013). Diagnostic and statistical manual of mental disorders. BMC Med, 17, 133-137.

2. Howlin, P., Magiati, I., \& Charman, T. (2009). Systematic review of early intensive behavioral interventions for children with autism. American journal on intellectual and developmental disabilities, 114(1), 23-41.

3. Center for Disease Control and Prevention.(2011). Morbidity and Mortality Weekly Report (MMWR). Measles- United States. Available at: http://www.cdc.gov/mmwr/preview/mmwrhtml/m m6115a1.htm?scid=mm6115a1 w\#fig1.Accessibility verified October 30, 2013.

4. Parker, S. K., Schwartz, B., Todd, J., \& Pickering, L. K. (2004). Thimerosal-containing vaccines and autistic spectrum disorder: a critical review of published original data. Pediatrics, 114(3), 793804.

5. Taylor, L. E., Swerdfeger, A. L., \& Eslick, G. D. (2014). Vaccines are not associated with autism: an evidence-based meta-analysis of case-control and cohort studies. Vaccine, 32(29), 3623-3629.

6. Fombonne, E., Zakarian, R., Bennett, A., Meng, L., \& McLean-Heywood, D. (2006). Pervasive developmental disorders in Montreal, Quebec, Canada: prevalence and links with immunizations. Pediatrics, 118(1), e139-e150.

7. Risher, J. F., \& Amler, S. N. (2005). Mercury exposure: evaluation and intervention: the inappropriate use of chelating agents in the diagnosis and treatment of putative mercury poisoning. Neurotoxicology, 26(4), 691-699.

8. Centers for Disease Control and Prevention (CDC. (2006). Deaths associated with hypocalcemia from chelation therapy--Texas, Pennsylvania, and Oregon, 2003-2005. MMWR. Morbidity and mortality weekly report, 55(8), 204. 
9. Brown, M. J., Willis, T., Omalu, B., \& Leiker, R. (2006). Deaths resulting from hypocalcemia after administration of edetate disodium: 20032005. Pediatrics, 118(2), e534-e536.

10. Davis, T. N., O'Reilly, M., Kang, S., Lang, R., Rispoli, M., Sigafoos, J., ... \& Mulloy, A. (2013). Chelation treatment for autism spectrum disorders: A systematic review. Research in Autism Spectrum Disorders, 7(1), 49-55.

11. Sharkey, S. (2000). Current indications for hyperbaric oxygen therapy. Adf health, 1(2), 64-72.

12. Calvert, J. W., Cahill, J., \& Zhang, J. H. (2007). Hyperbaric oxygen and cerebral physiology. Neurological research, 29(2), 132-141.

13. Granpeesheh, D., Tarbox, J., Dixon, D. R., Wilke, A. E., Allen, M. S., \& Bradstreet, J. J. (2010). Randomized trial of hyperbaric oxygen therapy for children with autism. Research in Autism Spectrum Disorders, 4(2), 268-275.

14. Rossignol, D. A., Rossignol, L. W., Smith, S., Schneider, C., Logerquist, S., Usman, A., \& Mumper, E. A. (2009). Hyperbaric treatment for children with autism: a multicenter, randomized, double-blind, controlled trial. BMC pediatrics, 9(1), 21.

15. Sampanthavivat, M., Singkhwa, W., Chaiyakul, T., Karoonyawanich, S., \& Ajpru, H. (2012). Hyperbaric oxygen in the treatment of childhood autism: a randomised controlled trial. Diving Hyperb Med, 42(3), 128-33.

16. US Food and Drug Administration. (2014). Beware of false or misleading claims for treating autism. FDA Consumer Health Information. Silver Spring: US Food and Drug Administration.

17. Sponheim, E. (1991). Gluten-free diet in infantile autism. A therapeutic trial. Tidsskrift for den Norske laegeforening: tidsskrift for praktisk medicin, ny raekke, 111(6), 704-707.

18. Marí-Bauset, S., Zazpe, I., Mari-Sanchis, A., Llopis-González, A., \& Morales-Suárez-Varela, M. (2014). Evidence of the gluten-free and casein-free diet in autism spectrum disorders: a systematic review. Journal of child neurology, 29(12), 17181727. 